\title{
$O$, the River is Deep and the Water Is Wide
}

I'm sitting at the Rose Garden Café in my front yard,

my half-blind, ailing, small grey cat

snoozing on the flagstone path beside the flowers.

This morning,

mid-September,

autumn's come early,

clad in naked air.

An edge of winter to the light.

The iron smell of snow in it,

although the sky's cloudless,

and the trees still green with the leaves of late summer.

I might be in the mountains of Thrace,

or that little town in Corfu, Pelikas,

sipping gritty black coffee in the stony square,

the sunlight sweet with the scent of cold pressed olives.

The whisper on the lips of it.

Perhaps if I walk far enough now,

listen hard enough, 
I'll hear it again,

put it in my pocket and carry it home.

$\mathrm{O}$, the river is deep

and the water is wide. 